\title{
Usos e abusos do formal e não formal em educação Uses and abuses of formal and non-formal education
}

\author{
Ricardo Vieira* \\ Ana Maria Vieira*
}

DOI: http://dx.doi.org/10.20435/231819822016102

\section{Resumo}

Este texto está dividido em dois andamentos. No primeiro andamento, procura-se desconstruir a dicotomia tão redutora entre formal e informal na Educação em geral e na Educação Social, em particular. Entendemos que a Pedagogia Social, mais interessada na (trans)formação pessoal e social, e a Antropologia da Educação, mais no estudo dos processos educativos, se interpenetram derrubando muros como o formal/não formal/informal e ainda o escolar e não escolar, salientando o processo educativo como um processo complexo e global que decorre entre o nascimento e a morte. Tanto uma como outra, a Pedagogia Social e a Antropologia da Educação, preferem atualmente, optar pelo uso da dimensão não escolar, por contraponto à lógica da escola, ao invés de não formal. O segundo andamento do texto centra-se na Pedagogia Social como ciência matriz da Educação Social (CARIDE, 2005) e nas competências do educador social que se autonomiza relativamente ao trabalho social pelo seu caráter pedagógico que determina os seus modelos de atuação, quer na escola, quer para além da escola, quer em espaços e tempos mais formais, quer menos formais.

\section{Palavras-chave}

Educação formal, informal e não formal; pedagogia social; educação social.

\begin{abstract}
This text is divided into two movements. In the first movement looking deconstruct as reductive dichotomy between formal and informal in general Education and Social Education in particular. We understand that the Social Pedagogy, more interested in the (trans) personal and social education, and the Anthropology of Education, more in the study of educational processes, interpenetrating knocking walls as formal / non-formal / informal and still the school and non-school, stressing the educational process as a complex and comprehensive process that takes place between birth and death. Both one and the other, Social Pedagogy and Anthropology of Education, now prefer to opt for the use of non-school size, compared with the school logic, rather than non-formal. In the second movement of the text focuses on social pedagogy as a science matrix of Social Education (CARIDE, 2005) and the powers of the social educator who becomes autonomous in relation to social work for its pedagogical character that determines their role models or at school, or beyond the school, both in space and time more formal or less formal.
\end{abstract}

\section{Key-words}

Formal, informal and no formal education; social pedagogy; social education

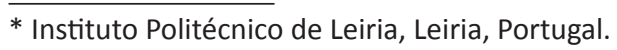




\section{QUESTIONANDO O FORMAL E O NÃO FORMAL NA EDUCAÇÃO}

São vários os autores (CARVALHO; BAPTISTA, 2004; CARVALHO, 2012; BAPTISTA, 2012; VIEIRA, 2013; VIEIRA; VIEIRA, 2015; CARIDE, 2005, entre outros) que aproximam a emergência da Educação Social, e da sua matriz teórica, a Pedagogia Social da Antropologia, uma vez que os Educadores Sociais agem em contextos socioculturais, comunitários ou grupais e com pessoas, elas próprias projetos antropológicos, na medida em que podem ter a capacidade de projetar, planificar, desejar, querer ser, querer construir determinada identidade pessoal, que é sempre sociocultural e auto e heteroconstruída (VIEIRA, 2009) com os pés no presente, mas com âncoras fundas na proveniência biográfica. Adalberto Dias de Carvalho e Isabel Baptista (2004, p. 9), pioneiros em Portugal a sistematizar fundamentos e estratégias da Educação Social, afirmam a propósito da delimitação epistemológica da Educação Social, que se trata de "um terreno tão tocado, como abandonado, pelas Ciências Sociais e Humanas, em geral, e pelas Ciências da Educação, em particular". É interessante como dedicam dentro do seu capítulo "Educadores Sociais uma identidade profissional em construção", um ponto justamente sobre "A cultura como veio antropológico da formação do educador social" no qual defendem que

[...] os projetos de intervenção, tendo de ser oportunos e efi- cazes, devem ser igualmente partilhados, inclusive, pelos próprios visados, por razões pragmáticas e filosóficas. É que a pessoa e os direitos humanos constituem referências antropológicas e jurídicas incontornáveis de tais atuações. (CARVALHO; BAPTISTA, 2004, p. 90).

Não deixa de ser curioso, também, como logo de início, na introdução ao mesmo livro, os autores deixam uma primeira crítica às dicotomias cartesianas tão queridas a muitos manuais sobre Educação Social, formal/informal e, também, ao escolar/não escolar:

[...] ao mesmo tempo, a Educação Social coloca um desafio incontornável: o de a educação ser vista como uma tarefa não apenas escolar mas que dimana de todas as instâncias sociais, conferindo-lhes coesão e projetos, ou, talvez melhor, coesão pelos projetos. (CARVALHO; BAPTISTA, 2004, p. 10).

Isabel Baptista (2012, p. 5), num artigo da revista Cadernos de Pedagogia Social, define, logo de início, a Pedagogia Social como representando

[...] justamente o domínio de conhecimento que, valorizando a educação em toda a sua amplitude socioantropológica, permite enquadrar a pluralidade de experiências socioeducacionais desenvolvidas em co- 
munidade e numa perspetiva de formação ao longo da vida.

Eis, pois, uma visão bem global de um campo a que Isabel Baptista designa de plural. Por seu lado, também num artigo de 2012, Adalberto Dias de Carvalho defende que a Pedagogia Social se joga

[...] nestes limites [a abertura radical ao diferente; e a tolerância que não se deve esgotar em si mesma] enquanto eles constituem autênticos limiares antropológicos - de inteligibilidade e de intervenção - designadamente para o trabalho social [...]. A ética da hospitalidade, entendida tal como nos é proposta por Innerarity, ou, por esta via, a receção do diverso e do frágil, implica, por isso, qualidades como a generosidade na medida em que esta signifique equilíbrio entre a proteção do eu e a abertura à alteridade. A figura eleita neste contexto é a do hospedeiro que, não mantendo uma relação de poder com o hóspede, o acolhe verdadeiramente, deixando-se inclusive, modificar algo, não se apropriando dele, isto é, como dissemos já, não fazendo dele refém. (CARVALHO, 2012, p. 37).

Relativamente à dicotomia formal / não formal, semelhante luta epistemológica tem tido a Antropologia da Educação, mais em particular com a Sociologia da Educação e, no caso dos EUA, em parte, com a Psicologia Cultural de que se aproxima muito quando estamos perante os trabalhos, por exemplo, de Bruner (2000) e de Geertz (2000). Bruner, que tem viajado da psicologia cognitiva para a psicologia cultural, fazendo assim uma aproximação à Antropologia, refere mesmo que estudar os processos educativos não é sinónimo de estudar o ensino e a aprendizagem na escola. Para ele "a educação não ocorre apenas nas aulas, mas à volta da mesa de jantar quando os membros da família fazem o confronto de sentido de tudo o que aconteceu ao longo do dia [...]" (BRUNER, 2000, p. 11). Amigo de Geertz, Jerôme Bruner chega mesmo a afirmar que "as fonteiras que separam campos como a Psicologia, a Antropologia, a Linguística ou a Filosofia eram mais questões de conveniência administrativa do que de substância intelectual" (BRUNER, 1997, p. 16).

Efetivamente, também a Antropologia da Educação pretende estudar todos os processos educativos, quer ocorram fora da escola, quer na escola ou no trajeto/processo entre os dois (VIEIRA, 1998), enquanto a Sociologia da Educação se tem situado mais na análise institucional e, em particular, na escola tornando-se, às vezes, mais numa Sociologia da escola do que numa Sociologia da Educação, muito embora haja muitos autores a articular, e bem, a escola e a família como relação fundamental do processo educativo (SILVA, 2003).

É verdade que, em Portugal, Raul Iturra sublinhou a tónica da Antropologia 
da Educação no estudo dos contextos extraescolares, coordenando, inclusivamente, uma coleção designada por "A aprendizagem para além da escola", onde foram publicados vários livros com enfoque nesse contexto: Fugirás à escola para trabalhar a terra: ensaios de Antropologia Social sobre o insucesso escolar de Raul Iturra (1990a); A construção social do insucesso escolar: memória e aprendizagem em Vila Ruiva de Raul Iturra (1990b); O corpo, a razão, o coração: a construção social da sexualidade em Vila Ruiva de Nuno Porto (1991); Corpos, arados e romarias: entre a fé e a razão em Vila Ruiva de Paulo Raposo (1991); Educação, ensino e crescimento: o jogo infantil e a aprendizagem do cálculo económico em Vila Ruiva de Filipe Reis (1991); O saber médico do povo de Berta Nunes (1997). Mas também é verdade que, mesmo nessa coleção, vieram a juntar-se outros livros com maior visibilidade e ênfase na escola: a Escola e aprendizagem para o trabalho num país da (semi)periferia europeia de Stephen Stoer e Helena Araújo (1992); e Entre a escola e o lar: o currículo e os saberes da infância de Ricardo Vieira (1992). Mas, efetivamente, o que Iturra sempre quis estudar e sublinhar nessa coleção da editora Escher, foi, exatamente, a descontinuidade que algumas crianças encontravam entre esses dois mundos ${ }^{1}$.

\footnotetext{
${ }^{1}$ É notável a definição de objetivos desta coleção, para o contexto da pedagogia social aqui discutida: "o objetivo desta coleção é dar a conhecer o saber que as pessoas retiram da sua experiência
}

O mais importante de tudo, neste texto, é deixar bem claro, agora, que a educação não remete apenas para a escola. Se o sentido corrente da palavra Educação e as próprias Ciências da Educação, tantas vezes, remetem o ensino e a aprendizagem para o domínio das aulas e das escolas, a verdade é que a Antropologia há muito que faz notar que a escolarização dá às crianças e jovens apenas um pequeno contributo para a inculturação e construção identitária. "Aprender, recordar, falar, imaginar, tudo isto é possibilitado através da construção numa cultura" (BRUNER, 2000, p. 11). E a criança não cai de paraquedas na escola. A criança que chega à escola já tem todo um percurso de construção cultural que lhe dá um entendimento para a vida e uma epistemologia com a qual se senta como aluno nas cadeiras da escola (ITURRA, 1990a e b).

[...] Quando falo de aprendizagem, falo da incorporação no grupo social dos novos membros que nele nascem. Esta incorporação faz-se segundo a memória que existe já no conjunto das pessoas, e por diversas vias. É na escola que se pensa, quando se fala em aprendizagem. Todavia, a criança, o sujeito que é incorporado, já aprendeu um conjunto de princípios, distinções e técnicas, por meio das quais

social, para suplementar o que a escola não ensina: a didática cultural da transmissão oral das ideias que o saber letrado não incorpora no ensino". 
a memória do grupo passa a ser parte do seu conhecimento e da sua própria lembrança. (ITURRA, 1990a, p. 51)

É nessa linha que entendemos que a Pedagogia Social, mais interessada na (trans)formação pessoal e social, e a Antropologia da Educação, mais no estudo dos processos educativos, se interpenetram derrubando muros como o formal/não formal/informal e ainda o escolar e não escolar, salientando o processo educativo como um processo complexo e global que decorre entre o nascimento e a morte. Ainda que, tanto uma como outra, a Pedagogia Social e a Antropologia da Educação, estejam historicamente situadas, inicialmente, na dimensão que, apesar de tudo, preferimos chamar de dimensão não escolar ao invés de não formal.

Ambas usam e se interessam pela observação participante, pela investigação-ação e pela etnografia dos contextos educativos na escola, fora da escola, na família, nos tempos livres etc., mas pretendem compreender também as metamorfoses culturais que ocorrem na vida dos indivíduos em consequência das convergências e divergências dos trajetos de vida face à cultura de partida. Assumem, assim, a importância já não tanto de uma Antropologia das culturas mas, antes, de uma Antropologia das pessoas (VIEIRA, 2009), elas próprias processos culturais em auto e heteroconstrução/reconstrução de si mesmas e da imagem que dão para os outros.
Também Dilthey enfatizou que a educação é uma função de toda a sociedade (portanto não é só da escola), o que obriga a pensar numa pedagogia menos centrada na escola e mais pensada nas relações sociais. Por isso urge, apesar da falsa dicotomia, reabilitar a educação não formal e pô-la em pé de igualdade. Nessa linha, e apesar de tudo, como já temos escrito, a ter de usar, por usar, dualismos, preferimos o da educação escolar/não escolar.

A Educação Social intervém, inicialmente, mais especificamente na educação não escolar mas, mais recentemente, como sabemos, ela tem vindo a ser acolhida por projetos dentro da escola, em Territórios Educativos de Intervenção Prioritária (TEIP), em Gabinete de Apoio ao Aluno e à Família (GAAF), resultado da compreensão de que o processo educativo é, afinal, como dissemos, antropológico, sempre social e não apenas pedagógico, e, logo, sociopedagógico.

O papel da Educação Social na escola, baseado numa Pedagogia Social, deve romper com as didáticas transmissivas, instrutivas e escolásticas em que as literacias acabam por se reduzir à leitura e à escrita e investir na Educação Social, de forma global, em termos de aprendizagem da convivência e da cidadania, sendo que a escola acaba por ser o primeiro laboratório social e espaço/tempo privilegiado para a aquisição dessas competências. E nós entendemos que o conviver, o saber viver entre diferentes, a interculturalidade, a inclusão remetem 
também para outras literacias que são parte da Pedagogia Social e quase sempre são ignoradas pela forma escolar.

Como referem Romains, Petrus e Trilla (2003, p. 63),

Até hoje, por motivos que não vêm ao acaso citar aqui, definíamos a Educação Social em contraposição à escola. Educação formal, não formal e informal tem sido uma terminologia que serviu para separar conceitualmente espaços educativo. Mas, atualmente resulta de todo incorreto recorrer a essa classificação, principalmente por ser imprecisa e criar confusão. Além do mais, não tem sido que por razões académicas separemos o que ocorre unido: Educação Social e educação escolar não são duas realidades opostas ou separadas. Pelo contrário, a realidade é uma, embora nós, desde a academia, pretendamos divorciá-la. Quando a sociedade e a universidade, felizmente começam a compreender o que é a Educação Social, reclamamos nossa presença nos espaços que por lógica são da nossa competência.

Finalmente, e ainda de acordo com Romains, Petrus e Trilla (2003, p. 60),

Reduzir a "educação" à "educação escolar" é ver apenas uma parte da realidade. E isso é mais perigoso, às vezes, do que não vê-la. Da mesma maneira que existem outros métodos, além dos didáticos, a educação não pode-se reduzir à educação formal. Ocorreu na educação o que, com palavras de Carlos Paris, poderíamos denominar "o rapto da cultura educativa" por parte da "cultura escolar". A escola não é a reserva natural da formalidade e do rigor pedagógicos. As outras educações, as mal chamadas "educações não-formais ou informais" podem ser tão formais, ou mais, que a própria escola. Existe de fato apenas uma educação. E o que Deus uniu que a Universidade não separe. A educação é global, e social e acontece ao longo de toda a vida. Se o objetivo da educação é capacitar para viver em sociedade e se comunicar, é preciso admitir que, em algumas ocasiões, a escola adota uma certa atitude de reserva frente aos conflitos e problemas sociais dos aluno.

\section{COMPETÊNCIAS DA PEDAGOGIA SOCIAL E DA EDUCAÇÃO SOCIAL EM ESPAÇOS FORMAIS E NÃO FORMAIS}

A Pedagogia Social é, habitualmente, considerada como ciência da Educação embora com um grande enfoque na vida fora da escola, na educação ao longo da vida, trabalhando de uma forma holística com as Ciências Sociais num mix criativo e interativo de domínios, por vezes, abusivamente, separados (BRUNER, 1999 e 2000). Efetivamente, a cultura e a vida social não podem ser separados, portanto, 
não podem passar à margem da escola. Dado este mix (VIEIRA, 2014) entre as Ciências Sociais e as Ciências da Educação, a Pedagogia Social é cada vez mais considerada um domínio científico transdisciplinar.

A Pedagogia Social, situada no contexto das Ciências Sociais e das Ciências da Educação, reflete-se, enquanto disciplina com vocação prática, na ciência da Educação Social (CARRERAS; MOLINA, 2006).

Desse modo, a Educação Social surge então associada à evolução da investigação e produção nas Ciências Sociais e da Educação, refletindo a responsabilização da sociedade perante as problemáticas sociais existentes e corresponde a um espaço profissional desenhado no ponto de encontro, e de cruzamento, entre a área do trabalho social e a área da educação.

De acordo com Adalberto Dias de Carvalho e Isabel Batista (2004), a Pedagogia Social fornece as ferramentas teóricas necessárias para uma intervenção no terreno que vise ajudar a tecer laços sociais e a criar situações de aprendizagem potenciadoras de felicidade, de bem-estar e de autonomia de vida.

A Pedagogia Social é um conjunto de saberes teóricos, técnicos, experienciais, descritivos ou normativos que tratam de um objeto determinado. Esse objeto é a Educação Social. A Educação Social pertence à ordem das práticas, processos e fenómenos, ou seja, da realidade socioeducativa.
A Pedagogia Social é a ciência matriz da Educação Social (CARIDE, 2005) devendo funcionar como saber profissional dos educadores sociais.

Portanto a Pedagogia Social é uma área científica com carácter teórico e prático que fornece as ferramentas para a intervenção prática, com e sobre os indivíduos, através da Educação Social, seja na escola, seja fora do espaço escolar. Dessa forma, autonomiza-se relativamente ao trabalho social pelo seu caráter pedagógico que determina os seus modelos de atuação.

O objetivo principal da Educação Social é incluir o indivíduo na sociedade. Procurar o sentido que nos proporciona a consciência dos vínculos que nos unem à Comunidade e a conduta que esses vínculos impõem. Tudo isto pode ser operacionalizado em três grandes objetivos principais da Educação Social: 1 - alcançar a maturidade social; 2 - promover as relações humanas e 3 - preparar o indivíduo para viver em sociedade. Relativamente ao primeiro objetivo, essa maturidade pode entender-se em diversos sentidos: Consciência dum objetivo comum, o que leva a uma aceitação do bem comum, subordinando o seu comportamento a esse objetivo; autodomínio; desenvolvimento das competências individuais e sociais, levando a um espírito de solidariedade, de dedicação aos outros e de cooperação para o bem comum; melhoria da qualidade de vida; espírito crítico em relação à sociedade; espírito 
de compreensão para com os outros; espírito construtivo que leva à procura da transformação da sociedade; espírito de harmonia, que implica otimismo, confiança, simpatia, alegria... Efetivamente, a maturidade social constitui um dos grandes objetivos da Educação Social. Ela requer uma série de competências que possibilitem as relações sociais, ou seja, viver em sociedade. Como, então, identificá-la como uma educação não formal? Como deixá-la navegar apenas para além da escola?

Relativamente ao 2o objetivo, promover as relações humanas, é fundamental que o educador social procure que cada cidadão vá em busca de seu lugar adequado na sociedade. Para o efeito, tem de favorecer o desenvolvimento da personalidade humana de modo que cada indivíduo seja capaz de lidar adequadamente com os outros, ou seja, desenvolver a sua capacidade para viver em sociedade, hábitos de convivência, respeito pelos outros, pela liberdade individual etc.

Finalmente, em relação ao 30 objetivo - preparar o indivíduo para viver em sociedade - isso passa, essencialmente por aprender a viver juntos (conviver), como muito bem sistematizou Jares (2007). E isso implica, também, desenvolver espírito crítico, desenvolver capacidade de intervenção na sociedade e promover atitudes sociais democráticas. Na verdade, a Educação Social deve proporcionar ao Homem a consciência do seu lugar na sociedade, para além do seu papel de produtor e consumidor. Deve consciencializá-lo para a participação democrática na vida das comunidades e, dessa forma, delas participar ativamente na melhoria das condições de vida (ser protagonista e exercer o seu direito de cidadania). E isto tem de ser promovido por todos os espaços e tempo educativos e não apenas pelas dimensões não escolares ou, pior ainda, "não formais".

Nunca é demais clarificar e sublinhar a importância preventiva da Educação Social assim como o trabalho social educativo. Efetivamente, quando nos referimos à Educação Social, referimo-nos, também, a um tipo de trabalho social de caráter educativo que desempenha funções pedagógicas procurando promover o bem-estar social. Referimonos a uma série de serviços sociais de caráter pedagógico que, por vezes, tendem a resolver problemas de carência de algo que atinge alguns grupos sociais situados mais nas franjas da sociedade e, outras vezes, procuram prevenir problemas da população em geral assegurando os meios (educação para a paz/convivência, educação ecológica, educação cívica, associativismo, voluntariado, ocupação de tempos livres... etc.) para que tal aconteça. Américo Peres (2010, p. 18-19) recorda a esse propósito que

[...] em resultado desta dinâmica, ao longo dos último anos, vários municípios, bairros, escolas, sindicatos, associações, ONG... têm desenvolvido, em contextos diversos, projetos relevantes para responder aos desafios do nosso século: 
aprender a viver e a conviver. Jares tinha consciência que a mediação contribuía para a resolução pacífica dos problemas e conflitos. Neste sentido, a figura do mediador deveria ser um educador que estabelecesse pontes entre as partes e, ao mesmo tempo, criasse relações humanas solidárias. Esta pedagogia da convivência aposta na criação de espaços e tempos de reflexão sobre os problemas da condição humana, nem como na afirmação da hospitalidade e no respeito pela alteridade dos seres humanos.

Também Adalberto Dias de Carvalho tem sido um grande promotor da ética da hospitalidade e do respeito pela alteridade que vai muito para além da simples tolerância e que obriga a uma nova atitude antropológica no acolhimento do Outro e que entende a ética [da hospitalidade] mais como uma moral do que um conjunto de princípios:

Por isso, não é tanto uma ética de princípios, mas antes de atenção e cuidado, a exigir sobretudo escuta aos apelos ou tão-somente aos sinais, principalmente dos que, fragilizados, sofrem e para com quem sentimos que temos o dever de evitar que esse sofrimento se agrave por força de uma solidão existencial. (CARVALHO, 2012, p. 36).

Tratando-se de um domínio científico novo, a Pedagogia Social, e de um campo de intervenção relativamente jovem, a Educação Social, é expectável encontrar não só diferentes definições de Educação Social bem como diferentes sublinhados sobre as principais funções que a definem.

A Educação Social atravessa, desse modo, várias linhas de ação e intervenção, entre as quais a construção da convivência, a busca de objetivos comuns, o investimento no relacionamento com os outros, de uma forma antropológica, como vimos, o desenvolvimento de competências sociais, em particular as práticas de inclusão, a consciência do lugar de cada sujeito na sociedade, a sua autonomização, a criação de laços sociais e o respeito pelas diferenças.

Para Carvalho e Baptista (2004, p. 7)

A Educação Social surge, actualmente, como um domínio de ponta. Enquanto plataforma agregadora de perspectivas disciplinares e de projectos de intervenção, ela estabelece relação entre o saber próprio do universo da pedagogia esta, tradicionalmente ligada à educação escolar - e a experiência da acção no terreno do trabalho social. Assim, ela impulsiona, cada vez mais, novos horizontes para a investigação e para um importante conjunto de profissionais.

Por outro lado, se considerarmos a Educação Social como prática da Pedagogia Social (CARIDE, 2005), ela "capacita as pessoas para a vida fugindo 
de uma perspectiva de comodismo que significa adaptação a um mundo dado. Antes pelo contrário, o que busca é o desenvolvimento pleno e autónomo das pessoas, cultivando as diversas dimensões humanas (afectiva, social, intelectual, física) (GRADAÍLLE; IGLÉSIAS, 2010, p. 70).

Apesar das divergências e de alguma falta de consenso, são habitualmente considerados três grupos de competências do educador social: 1 - conhecimentos; 2 - capacidades; 3 - atitudes. Relativamente aos conhecimentos mais específicos, já que os gerais têm a ver a com a formação profissional para o desempenho da função de educador social, consideram-se habitualmente os seguintes: conhecimento do meio (tipo de população, níveis culturais, socioeconómicos, profissionais, necessidades sociais...); conhecimento das metodologias mais apropriadas para intervir com o setor da população a que se dirige; conhecimento das suas funções para intervir; conhecimento das suas capacidades e limitações no desempenho do seu trabalho.

Em relação às capacidades, é de considerar, essencialmente, as seguintes: capacidade de elaborar projetos educativos; capacidade para intervir no educativo; capacidade de trabalhar em equipa; capacidade de formação contínua; capacidade para gerir recursos, entre outras.

Finalmente, em relação às atitudes, é de sublinhar as capacidades/ habilidades sociais: capacidade de comunicação, capacidade de trabalhar em equipa, capacidade de negociação, capacidade de empatia, escuta, atitude positivas, ativas e solucionadoras de problemas.

Claro que, em qualquer profissão, são importantes as dimensões técnicas, mas, numa profissão em que impera a relação interpessoal e social, são vitais as atitudes e a capacidade de refletir sobre estas e sobre as práticas quotidianas, seus sucessos e insucessos. Por isso, também, convém dizer que o educador social é um profissional reflexivo. Os educadores sociais não podem ser consumidores passivos de conceitos e de valores sociais. Como muitas vezes trabalham com populações fragilizadas, esses profissionais desenvolvem uma especial sensibilidade social preconizando, assim, a necessidade de uma mudança social. Podemos, então, pensar num estilo de educador social impulsionador da mudança social.

Em síntese, as competências, o saber profissional do Pedagogo/Educador Social, assentam muito na reflexividade, na polivalência técnica, na criatividade, na adaptabilidade e no dinamismo psicossociocultural.

A formação de um profissional, claro está, tem de ser assumida para toda a vida e não apenas para um determinado tempo biográfico no qual se adquiririam as competências fundamentais para o exercício da profissão: "No caso concreto dos educadores sociais, acontece que estes têm que estar preparados para adquirirem novas competências de 
acordo com aquelas que são as exigências da própria sociedade, sob pena de a sua actividade perder todo o sentido" (CARVALHO; BAPTISTA, 2004, p. 89).

Por outro lado, ainda, há outra ideia, que é mais ou menos habitual no "senso comum" das pessoas e dos profissionais em geral, que é considerar que, perante uma sociedade que é complexa, porque a diversidade sociocultural abunda, porque os problemas abundam, tem de haver alguém capaz de resolver, magicamente, os problemas sociais. Trata-se de ver os Gabinetes de Psicologia (SPO) ou o Gabinete de Apoio ao Aluno e à Família (GAAF) como espaços de enfermagem ou medicina social (VIEIRA; VIEIRA, 2011) e de pensar nos problemas sociais como doença e nos cuidados paliativos a ter com eles (CANÁRIO; ALVES; ROLO, 2001).

Há, efetivamente, no Trabalho Social, uma área designada de Serviço Social, e não estamos a remeter especificamente para uma profissão, que engloba não só os profissionais superiores, técnicos superiores, mas que abarca, também, o voluntariado, o trabalho dos enfermeiros, dos médicos, do apoio etc. que está mais perto da intervenção, enquanto resolução dos problemas detetados (CAPUL; LEMAY; 2003; CHOPART, 2003). Esse trabalho de Serviço Social está, enquanto área do Trabalho Social, mais próximo do "fim da linha", da resolução dos problemas do que, propriamente, da prevenção e da educação, mesmo quando aplicado à Educação. Esse trabalho corresponde, maioritariamente, à política paliativa de que falam Canário, Alves e Rolo (2001), fundamental, também, claro.

Mas o Trabalho Social corresponde, também, do nosso ponto de vista, a uma área mais ampla, que integra as anteriores (a Educação Social mais ligada à prevenção e à formação; a do Serviço Social mais ligada à resolução), e que é, igualmente, um domínio importante de atuação dos Educadores Sociais dentro das escolas contemporâneas, como exploramos neste artigo. O trabalho social pode englobar a dimensão mais educativa, mais construtora, preventiva, transformadora, mais próxima da Educação Social, definida atrás, alimentada pela Pedagogia Social (CAPUL; LEMAY, 2003; CARIDE, 2005; CARVALHO; BAPTISTA, 2004; BAPTISTA, 2008b) ou o trabalho social pode apostar mais na resolução dos conflitos, naquilo que Michel Foucault chamou de "ortopedia social" (FOUCAULT, 1977), naquilo que temos vindo a designar de o profissional como o "médico social" ou o "enfermeiro social"; a área do Trabalho Social como o "hospital social": o Serviço Social como hospital social para resolver os problemas (VIEIRA;VIEIRA, 2010 e 2011).

O trabalho do educador pode inserir-se, assim, nos domínios das crianças, adolescentes, jovens e idosos, mas não só; abrange os conceitos tradicionais de "educação permanente", "popular", "educação de adultos", "dos pais" etc., mas está, também, para além deles, em termos transversais e globais (CAPUL; LEMAY, 2003, p. 14). 
A Pedagogia Social, que Caride (2005, p. 37) exprime como "referente científico da Educação Social", apresenta intervenções e finalidades que promovem o desenvolvimento humano e a qualidade de vida. Para o efeito, ela tem de enfrentar as situações de risco que inibem ou dificultam a integração social, especialmente dos mais expostos aos processos de exclusão social, precariedade e dependência, e o compromisso de conquista de uma sociedade mais igualitária, justa e unida (CARIDE, 2005) e deve funcionar como saber profissional de referência dos educadores sociais (CARVALHO; BAPTISTA, 2004).

Caride enumera seis grandes áreas de intervenção da Pedagogia Social: a educação permanente, a formação laboral e ocupacional, a educação no/para o tempo livre, a Animação Sociocultural e o desenvolvimento comunitário, a educação especializada e a educação cívico-social: "A Pedagogia Social surge-nos deste modo valorizada simultaneamente como um saber profissional, uma ciência em construção e uma filosofia de acção, onde as práticas de mediação ganham especial importância" (RODRIGUES, 2010, p. 320). De acordo com Isabel Baptista (2000),

Neste sentido, o termo "social" junta-se ao termo "pedagogia" designando um objecto de estudo e um território de acção específicos mas também, ou sobretudo, um objectivo: o de encontrar estratégias de mediação humana que ajudem a "fazer sociedade". Pode-se dizer que a Pedagogia Social nasce de uma relação de hospitalidade originária entre a esfera educacional e a esfera da solidariedade social, correspondendo nesse plano a um espaço novo, a um "terceiro lugar» ou "lugar-comum".

Os trabalhos de "presença social" permitem uma escuta social imediata e pressupõem um contacto direto com o público nos "lugares de proximidade e de quotidianidade". Não implicam nem acompanhamento permanente, nem tratamento. Têm a ver com funções de acolhimento, aconselhamento e orientação. São os chamados "trabalhos de primeira linha". No patamar seguinte, estão os trabalhos de acolhimento e os trabalhos de rua. Os trabalhos de acolhimento podem arrumar-se, essencialmente, em dois modelos: o modelo de "auxiliar social" (tarefas de avaliação, orientação, instrução de dossiês e organização de procedimentos) e o modelo de animação (relacionamento dos vários atores, difusão das informações, deteção de pedidos e mediação social). Os trabalhos de rua são os mais recentes - algumas funções: por ex. mediação entre os habitantes de um bairro e organismos doadores, serviços municipais para resolverem problemas da vida quotidiana... Baseiam-se numa "função de mediação e de regulação de proximidade [...] aliando-se o técnico e o social" (cf. MAUREL, 2003, p. 42). 
Mas vivem-se tendências ora de qualificação das tarefas de primeira linha, ora de tentativa de especialização das tarefas de intervenção (MAUREL, 2003). Contudo o certo é que não se pode considerar, à partida, que o trabalho social seja construído como um campo já delimitado, uniforme e perfeitamente conhecido. A esse propósito, Michel Autés (2003, p. 256) refere que as transformações no seio das profissões giram em torno de 3 linhas: 1 - uma passagem da lógica do projeto à lógica do serviço; 2 - a instalação de uma fratura entre profissões de contacto direto e profissões ligadas aos procedimentos formais ou de organização; 3 - a tendência para a separação das profissões entre ação individual de reparação e ação coletiva de desenvolvimento. Para esse mesmo autor, "O termo 'trabalho social' está longe de designar um campo unificado. Ele foi construído segundo genealogias separadas (o Serviço Social, a Educação Social, a animação), tendo, cada geração, os seus próprios eixos de clivagem e as suas tradições históricas" (AUTÉS, 2003, p. 257).

Finalmente, não será abusivo dizer, para terminar, e de uma forma mais substantiva, que há consenso sobre algumas grandes áreas de intervenção da Educação Social na atualidade: educação de adultos, educação especializada, educação laboral e ocupacional; educação para o tempo livre; educação cívica; educação comunitária; educação para a saúde; educação penitenciária, trabalhando, por exemplo, diretamente com reclusos em dinâmicas ocupacionais de reabilitação, ou, no exterior, com as famílias, no sentido de contribuir para abrir caminhos de reinserção familiar e profissional; educação intercultural; educação ambiental, Educação Social em contexto escolar, Educação Social de rua, trabalho autárquico, promoção de práticas de relação intergeracional, usando, por exemplo, histórias de vida (VIEIRA, 2014, a e b) no trabalho com a 3aidade.

\section{CONCLUINDO}

A ciência moderna tudo quis classificar, reduzindo, tantas vezes, a realidade educativa, e não só, aos seus extremos. Assim, as classificações científicas chegaram ao séc. XX muito centradas em categorias binárias ou dualistas.

Na educação, pese embora a crítica a esse falso dualismo da educação formal e informal, desde os anos 70 do séc. $X X$, até porque, por vezes, há educações familiares bem mais formais que a da escola, persiste essa arrumação a partir, essencialmente, do olhar escolar (escolástico).

Se é verdade que toda a educação tem de ser social, a verdade é que houve necessidade de criar o conceito de Educação Social, justamente por a escola funcionar para alunos, para números da turma, despidos de cultura, e não tanto para sujeitos/cidadãos que têm de aprender as literacias contemporâneas mas, também, a da cidadania e da interculturalidade. 
A Educação Social tem como objetivo a formação do indivíduo para a convivência, para o relacionamento com os outros, para a inserção na sociedade e para a formação de uma consciência social e de uma identidade pessoal, de género, social e cultural pelo que se inscreve num processo que se estende entre o nascimento e a morte dos sujeitos.
A Pedagogia Social nasce de uma relação de hospitalidade originária entre a esfera educacional e a esfera da solidariedade social. Assim, o pedagogo social atua na socialização do sujeito, em situações normalizadas ou especiais. E isto implica o conhecimento e a ação sobre o indivíduo e a atuação no âmbito da Educação Social, seja na escola, seja fora dela.

\section{REFERÊNCIAS}

AUTÉS, Michel. As metamorfoses do trabalho social. In: CHOPART, Jean-Noel (Org.). Os novos desafios do trabalho social, dinâmicas de um campo profissional. Porto: Porto Editora, 2003. p. 255-278.

BAPTISTA, Isabel. Pedagogia social, um campo plural de investigação e intervenção. Cadernos de Pedagogia Social, n. 4, p. 5-8, 2012.

. Educador social: especialistas de mãos vazias. A Página da Educação, ano 9, n. 94, p. 19, set. 2000.

BRUNER, Jerôme. Actos de significado, Lisboa: Edições 70, 1997.

. Para uma teoria da educação. Lisboa: Relógio D’Água, 1999.

. Cultura e educação. Lisboa: Ed. 70, 2000.

CANÁRIO, Rui; ALVES, Natália; ROLO, Clara. Escola e exclusão social. Lisboa: Educa, 2001.

CAPUL, Maurice; LEMAY, Michel. Da educação à intervenção social. Porto: Porto Editora, 2003. v. I e II.

CARIDE, J. A. Las fronteras de la Pedagogia Social: perspectiva científica e histórica. Barcelona: Gedisa Editorial, 2005.

CARRERAS, Juan Sáez; MOLINA, José G. Pedagogia social: pensar a educação social como profissão. Madrid: Alianz Editorial, 2006.

CARVALHO, A.; BAPTISTA, I. Educação social: fundamentos e estratégias. Porto: Porto Editora, 2004.

CARVALHO, Adalberto Dias. Antropologia da exclusão ou o exílio da condição humana. Porto: Porto Editora, 2012.

CHOPART, Jean-Noel (Org.). Os novos desafios do trabalho social, dinâmicas de um campo profissional. Porto: Porto Editora, 2003. 
FOUCAULT, Michel. Vigiar e punir. Petrópolis, RJ: Vozes, 1997.

GEERTZ, C. Avaiable light: anthropological reflections on philosophical topics. New Jersey: Princeton University Press, 2000.

GRADAÍlLE, Rita Pernas; IGLESIAS, Tânia. Educando en igualdade nos escenarios escolares e sociais. In: PERES, Américo; VIEIRA, Ricardo (Org.). Educação, justiça e solidariedade na construção da paz. Chaves; Leiria: APAP/CIID-IPL, 2010. p. 60-74.

ITURRA, Raul. Fugirás à escola para trabalhar a terra - ensaios de Antropologia social sobre o insucesso escolar. Lisboa: Escher, 1990a.

. A construção social do insucesso escolar - memória e aprendizagem em Vila Ruiva. Lisboa: Escher, 1990b.

JARES, Xesus, Rodrigues. Pedagogia da convivência. Porto: Profedições, 2007.

MAUREL, Élisabeth. Da observação à tipologia dos trabalhos sociais. In: CHOPART, Jean-Noel (Org.). Os novos desafios do trabalho social, dinâmicas de um campo profissional. Porto: Porto Editora, 2003. p. 35-62.

NUNES, Berta. O saber médico do povo. Lisboa: Escher, 1997.

PERES, Américo. Introdução. In: PERES, Américo; VIEIRA, Ricardo (Org.). Educação, justiça e solidariedade na construção da paz. Chaves e Leiria: APAP e CIID-IPL, 2010. p. 9-29.

PORTO, Nuno. O Corpo, a Razão e o Coração: a construção social da sexualidade em Vila Ruiva, Lisboa: Ed. Escher, 1991.

RAPOSO, Paulo. Corpos, arados e romarias: entre a fé e a razão em Vila Ruiva. Lisboa: Escher, 1991.

REIS, Filipe. Educação, ensino e crescimento. Lisboa: Escher, 1991.

RODRIGUES, Cláudia. A mediação sociopedagógica: uma perspetiva de transformação. In: PERES, Américo; VIEIRA, Ricardo (Org.). Educação, justiça e solidariedade na construção da paz. Chaves e Leiria: APAP e CIID-IPL, 2010. p. 319-329.

ROMANS, M.; PETRUS, A.; TRILLA, J. Profissão educador social. Porto Alegre, RS: Artmed, 2003.

SILVA, Pedro. Escola-família, uma relação armadilhada. Porto: Edições Afrontamento, 2003. STOER, S.; ARAÚJO, H. Escola e aprendizagem para o trabalho. Lisboa: Escher, 1992.

VIEIRA, A.; VIEIRA, R. A educação proibida. Página da Educação, série II, verão, p. 40-41, 2015. . A patologização da diferença em territórios escolares. Página da Educação, série II, p. 48, 2010.

. Territórios educativos e mecanismos de lidar com a diferença na escola. In: ENCONTRO DE SOCIOLOGIA DA FLUP - Educação, Territórios e Desigualdades, 2., 2011, Anais... Porto: FLUP, 2011. p. 317-335. 
VIEIRA, Ana. Educação social e mediação sociocultural. Porto: Profedições, 2013.

VIEIRA, Ricardo. Entre a escola e o lar: o currículo e os saberes da infância. Lisboa: Fim de Século, 1992.

VIEIRA, Ricardo. Identidades pessoais. Interacções, campos de possibilidade e metamorfoses culturais. Lisboa: Colibri, 2009.

. Life stories, cultural métissage and personal identities. SAGE Open, v. 4, n. 1, p. 1-13, jan. 2014a. Available in: <http://sgo.sagepub.com/content/4/1/2158244013517241>. . Integração social na terceira idade. Ambientes promotores de envelhecimento ativo. In: AZEVEDO, S.; CORREIA, F. Educação e integração social. CONGRESSO INTERNACIONAL DE EDUCAÇÃO SOCIAL, 3., Porto, 2014. Anais... Porto: APTSES; Fronteira do Caos Editora, 2014b. p. 107-12.

\section{Sobre os autores:}

Ricardo Vieira: Mestre em Antropologia Social e Sociologia da Cultura (FCSHUNL). Doutor em Antropologia Social, Pós-Doutor em Serviço Social e Agregado em Antropologia da Educação (ISCTE-IUL). Atualmente é Professor Coordenador Principal (Profesor Titular) da Escola Superior de Educação e Ciências Sociais do Instituto Politécnico de Leiria, profesor Decano do Instituto Politécnico de Leiria e Investigador do Centro de Investigação Interdisciplinar de Ciências Sociais da Universidade Nova de Lisboa (CICS.NOVA.IPLeiria). E-mail: rvieira@ipleiria.pt

Ana Maria Vieira: Doutorada em Ciências da Educação, na área da educação social e mediação sociopedagógica. Assistente Convidada do Instituto Politécnico de Leiria e investigadora do Centro de Invesgigação Identidade(s) e Diversidade(s) do Instituto Politécnico de Leiria, Portugal (CIID-IPL).

\section{Recebido em fevereiro de 2016.}

Aprovado para publicação em março de 2016. 